Castro, A., Completo, A., Simões, J.A., Flores, P., Biomechanical behaviour of cancellous bone on patellofemoral arthroplasty with journey prosthesis: A finite element study. Computer Methods in Biomechanics and Biomedical Engineering, Vol. 18(10), pp. 1090-1098, 2015.

\title{
Biomechanical behaviour of cancellous bone on patellofemoral arthroplasty with journey prosthesis: a finite element study
}

\author{
A.P.G. Castro \\ Center for Mechanical and Materials Technologies \\ University of Minho \\ Campus of Azurem \\ 4800-058 Guimaraes, Portugal \\ Telephone: +351253510220 \\ Fax:+351253516007 \\ E-mail: apgcastro@dem.uminho.pt \\ António Completo \\ Department of Mechanical Engineering \\ University of Aveiro \\ Campus of Santiago \\ 3810-193 Aveiro, Portugal \\ Telephone: +351234370200 \\ Fax:+351234370985 \\ E-mail:completo@ua.pt \\ José A. Simões \\ Department of Mechanical Engineering \\ University of Aveiro \\ Campus of Santiago \\ 3810-193 Aveiro, Portugal \\ Telephone: +351234370200 \\ Fax: +351234370985 \\ E-mail:josesimoes@ua.pt \\ Paulo Flores (Corresponding Author) \\ Center for Mechanical and Materials Technologies \\ Department of Mechanical Engineering \\ University of Minho \\ Campus of Azurem \\ 4800-058 Guimaraes, Portugal \\ Telephone: +351253510220 \\ Fax:+351253516007 \\ E-mail:pflores@dem.uminho.pt
}




\section{Biomechanical behaviour of cancellous bone on patellofemoral arthroplasty with journey prosthesis: a finite element study}

Isolated patellofemoral (PF) arthritis of the knee is a common cause of anterior knee pain and disability. Patellofemoral arthroplasty (PFA) is a bone conserving solution for patients with PF degeneration. Failure mechanisms of PFA include growing tibiofemoral arthritis and loosening of components. The implant loosening can be associated with bone resorption, or fatigue-failure of bone by overload. This research work aims at determining the structural effects of the implantation of PF prosthesis Journey PFJ (Smith\&Nephew, USA) on femur cancellous bone. For this purpose, the finite element (FE) method is considered to perform computational simulations for different conditions, such as well-fixed and loosening scenarios. From the global results obtained, in the well-fixed scenario, a strain decrease on cancellous bone was noticed, which can be related to bone resorption. In the loosening scenario, when the cement layer becomes inefficient, a significant increase of cancellous bone strain was observed, which can be associated with bone fatigue-failure. These strain changes suggest a weakness of the femur after PFA.

Keywords: knee; cancellous bone; finite element method; patellofemoral arthroplasty 


\section{Introduction}

Isolated patellofemoral (PF) arthritis of the knee articulation is a common cause of anterior knee pain and disability, affecting approximately $10 \%$ of the population in general (Argenson et al. 2005; Leadbetter et al., 2006). Patellofemoral arthroplasty (PFA) is a bone conserving solution for patients with isolated PF degeneration, after other surgical options have failed (Delanois et al. 2008; van Jonbergen et al. 2012; Muller et al. 2012). This technique is mainly recommended for patients under 55 years old with isolated anterior compartment arthrosis, allowing, if necessary, for the total knee arthroplasty to be performed later (Mont et al. 2008; Castro et al. 2012). PFA was firstly presented in the 1950's by McKeever (1955) followed by DePalma and his coworkers (1960), being the designs materials and surgical procedures improved over the last decades. Despite PFA has been object of intensive investigation, this type of treatment is not yet widely accepted (Arnbjörnsson and Ryd, 1998; Carr and Goswami 2009). Typical failure mechanisms of PFA include patellar maltracking and growing tibiofemoral arthritis. Failure, wear and loosening of components have also been reported (Arciero and Toomey 1998; Tauro et al. 2001; Looner 2002; Smith et al. 2002; Kooijman et al. 2003; Board et al. 2004; Argenson et al. 2005; Cartier et al., 2005). The implant loosening can be related to bone resorption, or fatigue-failure of bone by overload. Several studies describe a significant decrease in postoperative bone mineral density, adjacent to the implants, after arthroplasty (Li and Nilsson 2000; Soininvaara et al. 2004). Bone resorption, due to stress-shielding, has been suggested as the primary mode of failure of cementless femoral prostheses (Sumner and Galante 1992; Ahmed et al. 1996; Smith et al. 2008). The stress-shielding effect is particularly observed on cancellous bone, causing a great number of surgeries for revision of the arthroplasty (Huiskes et al. 1997). As stated by Wolff's law for bone remodelling, the stressshielding effect may lead to bone failure through osteopenia. In addition, the failure 
process in the cancellous bone can also be produced by high strains, which ultimately will cause bone rupture by fatigue. Fatigue-failure of bone is characterized clinically by repetitive loading, bone resorption and growing pain (Wright and Burstein 1994; Taylor et al. 2002; Olsen et al. 2010). It has been recognized that bone suffers fatigue-failure if the induced stress approaches 60 to $80 \%$ of the yield strength. In short, stress-shielding or overload modes in cancellous bone may continue until gross resorption, subsidence, or dislocation occur (Olsen et al. 2010; Castro et al. 2012).

The present work deals with the modelling, simulation and analysis of the structural effects of PFA with a commercial Journey PFJ prosthesis on the cancellous bone. For this, two different cancellous bone interface conditions are considered, namely the well fixed and loosening scenarios of the prosthesis. This paper extends previous' authors work (Meireles et al. 2010) in which natural and implanted femur were utilized to simulate different activities of daily living, such as walking and deep bending. In the sequel of this process, the FE models have been validate with experimental data (Meireles et al. 2010). Thus, in the present study, the strains in cancellous bone were compared for both natural and implanted conditions. Furthermore, the risks associated with the strain changes were presented and discussed in the light of the different bone-implant interface scenarios. This work has been motivated by lack of studies on the state of strain/stress on PFA, therefore, it is required that further analyses on the mechanical effects caused by the PF replacement are required, in order to improve the performance of this type of solutions.

\section{Materials and Methods}

In the present work, natural and implanted femur geometrical models are studied. The natural femur geometry was based on physical 3D model 3406 from Sawbones ${ }^{\circledR}$ (Pacific Research Lab, Inc., Vashon Island, WA, USA). It has been 
demonstrated that axial, bending and torsional stiffness of the composite and strain distribution in this femur physical model are similar to those occurring in natural human bones (Heiner 2008). In turn, the implanted femur model was developed with basis on the natural femur implanted with a cemented femoral component of PF prosthesis from Smith \& Nephew (USA), denominated hereafter as Journey PFJ. The prosthesis models were created using a CAD modelling package (Catia V5, Dassault-Systèms, France) after 3D digitalization with a 3D laser scanner device (Roland LPX 250). Patellofemoral articulation prosthesis (patellofemoral arthroplasty) from Smith \& Nephew, Inc. (Memphis, TN, USA) was used. The implant is composed of oxinium, created from a compound of $97.5 \%$ zirconium and $2.5 \%$ niobium. The oxinium material is a metal with the surface transformed into ceramic. Oxygen diffuses into zirconium creating a 5-mthick ceramic surface, and leaving a metal core to retain strength and flexibility. Under the patella, an ultra-high molecular weight polyethylene (UHMWPE) patellar prosthetic component is implanted. The patellofemoral replacement surgery was made into the intact femur by an experienced surgeon. The in vitro insertion procedure was performed according to the protocol described for this type of patellofemoral prosthesis. Triaxial (rosette) strain gauges (KFG-3-120-D17-11L3M2S, Kyowa Electronic Instruments Co., Ltd., Japan) were glued to the femur at five anatomical locations, namely, two gauges onto the distal region (medial and lateral superior sides), one on the anterior side surface and the other ones were placed on the lateral and medial side of the condyles surface. All strain gauges were connected to a data acquisition system PXI-1050 from National Instruments (Texas, United States). The interested reader in the detailed description on these pre-processing procedures is referred to the work by Meireles and her co-authors (2010). In the present study, the two bone layers, namely the compact and cancellous, compose the natural femur model. The implanted femur model includes the cement 
layer and the prosthesis, provided that the bone layers are equal on both models (Figure 1). The FE meshes of the natural and implanted models were built using meshing software HyperMesh v8.0 (Altair-Engineering, USA). In turn, the finite element analyses (FEA) were performed by employing the commercial program Marc ${ }^{\circledR}$ Mentat 2005 (MSC Software, USA).

\section{Figure 1}

FEA can be significantly affected by the definition of boundary conditions, material proprieties and contact conditions. In this study, the materials utilized are considered to be homogeneous, isotropic and linear elastic, as it is listed in Table 1 (Completo et al. 2009; Meireles et al. 2012; Kirane et al. 2012). The cement bone interface was characterized by two different conditions. The first one represents a wellfixed prosthesis that corresponds to the health scenario, while the second condition simulates a loose prosthesis, which characterizes the loosening scenario. In the health scenario, the cement acts perfectly, and therefore it is rigidly bonded to both bone and implant. In the present study, this condition is designated as "all glued". When the life of the implant advances, loosening may start to occur, which corresponds to the loosening scenario described above. With the purpose to simulate this condition, a value of coefficient of friction equal to unity is considered for the cement-bone interface. This situation has been demonstrated to be appropriate for this type of studies, as it can be found in the work by Completo and his co-workers (2008a; 2009). In fact, this premise intends to simulate a mid/long-term clinical scenario, based on the radiolucent lines, which are usually visible at the interface. The coefficient of friction value is associated with the capability of the cement to fill the cavities of the cancellous bone and offer great resistance to slip, and at the same time allows interface separation. The "with 
friction" case is a simplified scenario of the debonding situation, that is, the presence of fibrous tissue in the interface is not taken into consideration. However, the authors are aware of the restrictions of such simplification, i.e., if the formation of fibrous tissue on the bone-cement interface was considered (Mann et al., 2012), the deformation of the bone would be somewhat different. In this study, this condition is denominated as "with friction". For this case, the contact between implant and cement was modelled with a friction coefficient of 0.25 (Mann et al. 1991). In the context of the present work, the classical dry Coulomb friction model is utilized to perform the computational simulations. The issue of friction modelling has particular influence on the biomechanical behaviour of the different scenarios of the cancellous bones. The interested reader on the detailed analysis of this topic is referred to the work by Mann et al. (1991) and Completo et al. (2008a; 2009).

\section{Table 1}

At this stage it must be mentioned that, prior the carry out the computational simulations, a convergence study was performed with the intent to verify the mesh quality of the natural FE model. For this purpose, the maximal displacements for this model were measured, being the stop criterion considered when the convergence rate for the displacements was less than $0.3 \%$ for 120000 degrees-of-freedom, which corresponds to the $2 \mathrm{~mm}$ elements.

In order to validate the FE models here presented, a linear regression analysis was performed to determine the overall correlation between numerical and experimental cortex strains. For this purpose, a published experimental data on the strain study of PFA was numerically replicated (Meireles et al. 2010). The principal strains of the FE models were computed and compared with experimental results at the same locations. 
The boundary conditions were equivalent to non-pathological level walking. In addition, the minimal principal strains (MPS) in cancellous bone under prosthesis were graphically analysed along three nodes alignments presented in Figure 2. These three alignments include the areas where the holes for the prosthesis' implantation were surgically created, because these areas are typically more willing to exhibit major strain concentration (Completo et al. 2008a). It must be highlighted that these alignments were exactly replicated for both natural and cement-bone interface conditions described above.

Figure 2

In this work, three load cases were considered and applied to the natural and implanted FE models (Table 2). These load cases are representative of three physiological activities, namely, climbing stairs $\left(45^{\circ}\right)$, descending stairs $\left(60^{\circ}\right)$ and isometric exercise $\left(90^{\circ}\right)$. All of these activities were characterized by the knee flexion angle, the patellofemoral joint reaction (PFJR) force and the two equal components of tibiofemoral joint reaction (TFJR) force corresponding to the medial and lateral femoral condyles (Reilly and Martens 1972; Matthews et al. 1977; Zavatsky et al. 2004; Completo et al. 2007; Li et al. 2007; Komistek et al. 2008). For both natural and implanted models, the computational simulations were performed by considering the proximal extremity of the femur fully constrained. This condition is here referred as "fixed displacement" (Figure 3). It must be highlighted that the same boundary conditions were considered for for both natural and implanted models. The application of a cyclic load, associated with fatigue, will produce the same levels of deformation as in the static model, because the materials utilized in the present work are isotropic and linear elastic in nature, that is, the viscoelastic and damage properties are not 
considered. Furthermore, the static conditions are used to evaluate the levels of deformation associated with fatigue. According to Choi and Goldstein (1992), bone is expected to suffer fatigue-failure if the induced strains approach 60 to $80 \%$ of the yield strength. These strain levels may occur if the normal maximum strains/stresses in the cancellous bone of natural joints are increased by 50 to $100 \%$ due to implantation of the prosthesis (Wright and Burstein 1994). In the present study, the applied loads were uniformly distributed over the physiological contact area of both patella and tibia on the femur. This approach has been described in detail in the work by Matthews et al. (1977), where the contact areas are well described which allows for proper validation. In the particular case of the patella, the methodology presented by Hehne (1990) and Duparc (2002) was considered here. Furthermore, the contact areas were the same for the case of natural and implanted models. In order to keep the analysis simple, for the particular case of 90 degrees, the contact between the patella and prosthesis was considered.

\section{Table 2}

Figure 3

\section{Results}

Figure 4 depicts the results in terms of the principal strains obtained from the numerical and experimental tests (Meireles et al. 2010). By performing a linear regression between numerical and experimental data, it can be concluded that the correlation is good enough with a correlation value $R^{2}$ equal to 0.8925 . This value can be affected by the numerical difficulties associated with the exact reproduction of the location of the applied loads in the experimental model, and also by the slight differences in the location of the strain gauges. This outcome ensures that the 
computational simulations can reproduce with significant fidelity the data obtained from experiments (Stolk et al. 2002, Meireles et al. 2010).

\section{Figure 4}

The diagrams plotted in Figures 5 and 6 relative to the minimal strains permit to compare the natural femur with the implanted model in both health and loosening scenarios represented by different contact conditions at the cement-bone interface ("all glued" or "with friction", respectively).

Thus, the strain results for the "climbing stairs" activity (45 degrees of knee flexion) for the model where the cement is rigidly fixed to bone ("all glued") showed a decrease of MPS relatively to the natural femur in all alignments analysed (Figure 5). The peak reduction (12 times less) was observed at the alignment 2 (line 2) at the proximal region (close to point $B$ ). The loose prosthesis model ("with friction") exhibited different strain behaviour in function of the analysed alignment. In the most medial alignment (line 1) the strain values were very close to the natural femur. In the central alignment (line 2), at the distal region (point $A$ ), a great significant (12 times higher) of minimal principal strain was observed, when compared to the natural femur. However, at the proximal region (close to point $B$ ), a strain reduction (2 times less) happened, relatively to the natural condition. At the most lateral alignment (line 3), a strain increase relatively to the natural femur was observed along all alignments, with a peak augmentation (12 times higher) at the distal region (point $A$ ).

The strain results for the "descending stairs" activity (60 degrees of knee flexion) were very similar to the aforementioned cases of to the "climbing stairs" activity, for both cement-bone interface conditions, as it is illustrated in Figure 5. 
The strain results at the "isometric exercise activity" (90 degrees of knee flexion), shown in Figure 6, present noticeable differences, when they are compare to the results from the other load cases. These differences are likely due to the increase of magnitude of the PFJR force, which almost double. Accordingly, higher levels of strain were observed on the cancellous bone, for both natural and implanted models. In the model in which the cement is rigidly fixed to bone ("all glued"), a decrease of MPS relatively to the natural femur occurs for all analysed alignments. Similarly, for the remaining load cases ("climbing stairs" and "descending stairs") the peak strain reduction (6 times less) happened at the central alignment (line 2). The loose prosthesis model ("with friction") showed the tendency of increased minimal principal strain, relatively to the natural femur, in a similar manner for others load cases. The exception is in central alignment (line 2), where a strain reduction occurs from mid alignment until proximal region (point $B$ ). When the friction is considered at the cement-bone interface, the effect of geometrical transition caused by the prosthesis pins is clearly noticed, corresponding to the observed peaks of strain.

\section{Figure 5}

Figure 6

\section{Discussion}

It is well known that the numerical studies can have some shortcomings, as it is the case of the present work. One limitation of this work is concerned with the validation of the numerical model relatively to an experimental with use of synthetic bones. The advantage of these analogue models is that their variability is significantly lower than that of cadaveric specimens for all loading regimens (Heiner 2008). In addition, the flexural and torsional rigidity of synthetic femur are within range of 
healthy adult bones, as well as the failure modes of this synthetic models were close to published findings for human bones (Gardner et al. 2010), however the clinically relevance can be always questionable. Nevertheless, due to the comparative nature of the study, these limitations would not change the major structural differences between intact and implanted condition.

As it was mention previously, the main objective of this work was to determine the structural effects of the implantation of PF prosthesis on femur cancellous bone. In fact, this issue has not been fully addressed in the thematic literature, in particular in what concerns with the evaluation of the state of strain/stress of PFA. For this, it is assumed that the nature and magnitude PF cyclic loads, with a commercial Journey PFJ, produces strain/stress on the bone that exceeds the fatigue strength of the materials used. On the one hand, level of stress should be kept moderate in order to avoid the loosening. On the other hand, these levels should also be high enough to prevent significant bone atrophy.

The first step of this work dealt with the validation of the FE models developed. For this, the experimental data available in the literature for the PF in-vitro case was used (Meireles et al. 2010). From the outcomes produced, it can be drawn the proposed models are consistent and accurate enough, being the numerical-experimental correlation good. The linear regression performed lead to a correlation value of $R^{2}=0.8925$. This observation is in line with the best-published studies (Stolk et al. 2002; Completo et al. 2008a; Completo et al. 2008b).

Two cement-bone interfaces were considered with the purpose of replicate two different clinical scenarios, namely the "health scenario" and the "loosening scenario". For the first case, the cement was considered rigidly bonded to both bone and implant, meaning that is no separation between the interfaces. In turn, the "loosening scenario" 
allows for the possible separation between cement and bone interfaces. The last case intents to simulate a mid/long-term clinical scenario, in the measure that in this interface radiolucent lines are usually visible in radiographic evaluations. This situation can be relevant to take a decision for revision as function of the extension of the gap revealed by the radiolucent line (Rubin and Lanyon 1985; Gross and Rubin 1995).

In the "health scenario", where the cement was considered rigidly bonded to the bone ("all glued"), a generalised strain reduction on cancellous bone was observed for the three different daily activities. This phenomenon, known as stress-shielding, can be explained by the load sharing capability of the implant. In fact, the loads applied to the trochlea surfaces are shifted, after the implantation, to the surrounding regions (bridge effect), unloading the cancellous bone under prosthesis. The extents of these strain reductions stood between 1 and 12 times lesser when comparison with the strain levels for the natural femur. The long-term implications of stress-shielding effect may be understood through Wolff's law. Besides the biological control mechanisms that produce the effect described by Wolff's law has not been yet well understood, it has been recognized that in situations in which bone loads are reduced or eliminated, the bone mass is reabsorbed (Rubin and Lanyon 1985; Gross and Rubin 1995). Thus, the extent of strain reduction after PFA suggest a risk of cancellous bone resorption for loads in range of daily activities.

In the "loosening scenario", where the cement was not bonded to the bone ("with friction"), a localized increase on cancellous bone strain was observed for the three different daily activities studied. The increase represent several times (1 to 12) the strains experienced in the natural case. The failure process in the cancellous bone tissue can occur due to overload or fatigue. Fatigue-failure of bone is characterized clinically by repetitive loading, a gradual increase on set pain, and bone resorption. This process 
can continue until gross resorption, subsidence, or even dislocation take place. Broadly, it is expected that bone can suffer fatigue-failure if the induced strains reach 60 to $80 \%$ of the yield strength (Choi and Goldstein 1992). These levels of strain may occur if the maximum strains/stresses in the cancellous bone of natural articulations increased by 50 to $100 \%$ due to implantation of the prosthesis (Wright and Burstein 1994). Thus, taking into account the increase of the strain between the implanted and natural states, a risk of fatigue-failure of cancellous bone is present after PFA, for loads in range of daily activities if the cement is not firmly bonded to the bone.

According to the best knowledge of the authors, there are no published biomechanical or clinical studies examining the strain behaviour in cancellous bone or even changes in mineral density of the cancellous bone after PFA. In addition to the failures of early-generation implants, a relatively high tendency for failures directly related to patellar maltracking has been identified (Arciero and Toomey 1988; Tauro et al. 2001; Board et al. 2004; van Jonbergen et al., 2010). Hendrix and his co-workers (2008) performed a review of these outcomes and concluded that although many of the failures have been attributed to component malposition or soft tissue imbalance, the likelihood is that many of them were, in fact, promoted by particular design features of the trochlear components, which put the patella at risk for catching, snapping, and subluxation on its proximal and lateral edges. Ackroyd and his co-authors analysed the results of the Avon prosthesis in 85 patients followed for at least five years. The 5-year survivorship was equal to $96 \%$, and the main complication was radiographic progression of arthritis in the other compartments, which was noted in 25 of the patients (Ackroyd and Newman 2001; Ackroyd et al. 2007). It must be stated that no clinical observations about using the Journey PF prosthesis have been reported. Bone loss or signal of osteopenia in the femur surrounding the PF prosthesis was not included in the 
above-mentioned clinical studies. Nevertheless, the outcomes produced here demonstrated a pronounced effect of stress-shielding in cancellous bone, when the prosthesis is rigidly bonded to the bone (health scenario), for the isometric exercise activity, which is not a common daily activity. For the most frequent daily activities, like climbing and descending stairs, the results here reported also exhibit a stressshielding effect. However, when compared with isometric exercise activity, this phenomenon occurred with a lower magnitude. This stress-shielding effect can influence the normal remodelling process of the physiological bone, which, consequently, affects its capability to maintain density and strength surrounding the implant (Frost 2004). Thus, the underloading can promote an early reduction of the bone density, bone resorption and eventually can contribute to failure of the implant support and lead to loosening. If the loosening occurs at the PFA, a localized state of overloading in cancellous bone is installed for all studied activities. This state can promote bone fatigue damage when the increase on the strain exceeds the fatigue strength of the host bone (Frost 2004). Thus, in order to obtain better results, the redesign of the available implants and the mode how they are connected to bone must be object of further investigation.

It must be highlighted that proposed approach is effective to analyse the stress/strain state within prosthesis components. However, particular attention must be given to the process of validating the outcomes, especially when modelling and simulating complex biological systems. One constraint associated with the present study is related to the forces applied in the measure that only the PFJR and TFJR reaction forces were taken into account. Thus, forces associated with quadriceps and patella ligament can have some influence of the systems biomechanical behaviour. However, this point was out of the scope of the present work (Mathews et al. 1977). Another issue 
that can be addressed in future investigations are those related with different prosthesis available in the market, since they may respond in a different manner (Müller et al. 2012). Finally, the influence of the homogeneity of the bone and cement layer, as well as the bone cuts and different pathological stages of the bone must be object of research.

\section{Conclusion}

The present work showed that the cancellous bone of the femur can be susceptible after the implantation of PF prosthesis. The outcomes demonstrated the effect of PFA with commercial PF prosthesis in bone structure, when compared with the natural joint for different loads associated with several daily activities. It was also presented that the stress-shielding effect is an important issue for the arthroplasty surgery. Finally, bone rupture by fatigue can occur on cancellous bone when the cement layer becomes inefficient. However, some efforts have to be done to improve the redesign and performance of PFA solutions.

\section{Acknowledgements}

The first author expresses his gratitude to Fundação para a Ciência e a Tecnologia (FCT) for the PhD scholarship SFRH/BD/63882/2009. The support of FCT through the project, PTDC/EME-PME/099764/2008, titled BIOJOINTS - Development of advanced biological joint models for human locomotion biomechanics is gratefully acknowledged.

\section{References}

Ackroyd CE, Newman JH, Evans R. 2007. The Avon patellofemoral arthroplasty: five-year survivorship and functional results. Journal of Bone and Joint Surgery - British. 89:310-315.

Ackroyd CE, Newman JH. 2001. The Avon patello-femoral arthroplasty: development and early results. Journal of Bone and Joint Surgery - British Volume. 83-B S II:146-147.

Ahmed AM, Tissakht M, Chan KC. 1996. Calculated stress-shielding in the distal femur after total knee replacement corresponds to the reported location of bone loss. Journal of Orthopaedic Research. 14(5):778-785.

Arciero R, Toomey H. 1988. Patellofemoral arthroplasty: A three to nine year follow-up study. Clinical Orthopaedics Related Research. 236:60-70.

Argenson JA, Flecher X, Parratte S. 2005. Patellofemoral arthroplasty: an update. Clinical Orthopaedics Related Research. 440:50-53.

Arnbjörnsson AH, Ryd L. 1998. The use of isolated patellar prostheses in Sweden 1977-1986. International Orthopaedics. 22:141-144. 
Board TN, Mahmood A, Ryan WG. 2004. The Lubinus patellofemoral arthroplasty: a series of 17 cases. Archives of Orthopaedic Trauma Surgery. 124:285-287.

Carr BC, Goswami T. 2009. Knee implants - Review of models and biomechanics. Materials and Design. 30:398-413.

Cartier P, Sanouiller JL, Khefacha A. 2005. Long-term results with the first patellofemoral prosthesis. Clinical Orthopaedics Related Research. 436:47-54.

Castro A, Completo A, Simoes JA, Flores, P. 2012. Development of a new femoral component for patellofemoral prosthesis. 2012 IEEE 2nd Portuguese Meeting in Bioengineering; Coimbra, Portugal. (http://dx.doi.org/10.1109/ENBENG.2012.6331394)

Choi K, Goldstein SA. 1992. A comparison of the fatigue behavior of human trabecular and cortical bone, Journal of Biomechanics. 25:1371-1381.

Completo A, Fonseca F, Simoes JA, Oliveira M. 2008a. The influence of different tibial stem designs in load sharing and stability at the cement-bone interface in revision TKA. The Knee. 15:227-232.

Completo A, Fonseca F, Simoes JA. 2007. Finite element and experimental cortex strains of the intact and implanted tibia. Journal of Biomechanical Engineering. 129:791-797.

Completo A, Fonseca F, Simoes JA. 2008b. Experimental evaluation of strain shielding in distal femur in revision TKA. Experimental Mechanics. 48(6):817-824.

Completo A, Fonseca F, Simoes JA. 2009. Revision total knee arthroplasty: The influence of femoral stems in load sharing and stability. The Knee. 16:275-279.

Delanois RS, McGrath MS, Ulrich SD, Marker DR, Seyler TM, Bonutti PM, Mont, MA. 2008. Results of total knee replacement for isolated patellofemoral arthritis: When not to perform a patellofemoral arthroplasty. Orthopedic Clinics of North America. 39(3):381-388.

DePalma AF, Sawyer B, Hoffman JD. 1960. Reconsideration of lesions affecting the patello-femoral joint. Clinical Orthopaedics. 18.

Duparc, J (2002) Femur and Knee. Surgical Techniques in Orthopaedics and Traumatology 7.

Frost HM. 2004. A 2003 update of bone physiology and Wolff's law for clinicians. Angle Orthodontist. $74: 3-15$.

Gross T, Rubin C. 1995. Uniformity of resorptive bone loss induced by disuse. Journal of Orthopaedic Research. 13(5):708-714.

Gardner MP, Chong AC, Pollock AG, Wooley PH. 2010. Mechanical evaluation of large-size fourthgeneration composite femur and tibia models. Ann Biomed Eng 38(3):613-620.

Hehne HJ. (1990). Biomechanics of the patellofemoral joint and its clinical relevance. Clin Orthop Relat Res. 258:73-85.

Heiner AD. 2008. Structural properties of fourth-generation composite femurs and tibias. Journal of Biomechanics. 41(15):3282-3284.

Hendrix MRG, Ackroyd CE, Lonner JH. 2008. Revision patellofemoral arthroplasty: Three- to sevenyear follow-up. The Journal of Arthroplasty. 23:983-997.

Huiskes R, van Lenthe GH, Malefijt MC. 1997. Stress-shielding after total knee replacement may cause bone resorption in the distal femur. Journal of Bone and Joint Surgery. 79(22):117-122.

Kirane YM, Lewis GS, Sharkey NA, Armstrong AD. 2012. Mechanical characteristics of a novel posterior-step prosthesis for biconcave glenoid defects. Journal of Shoulder and Elbow Surgery. 21(1):105-115.

Komistek RD, Mason JJ, Leszko F, Johnson T. 2008. Patellofemoral joint forces. Journal of Biomechanics. 41:2337-2348.

Kooijman HJ, Driesen AP, van Horn JR. 2003. Long-term results of patellofemoral arthroplasty: A report of 56 arthroplasties with 17 years of follow-up. Journal of Bone and Joint Surgery - British Volume. 85:340-836.

Leadbetter WB, Seyler TM, Ragland PS. 2006. Indications, contraindications and pitfalls of patellofemoral arthroplasty. Journal of Bone and Joint Surgery. 88:122-137. 
Li G, Nilsson KG. 2000. Changes in bone mineral density at the proximal tibia after total knee arthroplasty. Journal of Orthopaedic Research. 18:40-47.

Li G, Papannagari R, Nha KW. 2007. The coupled motion of the femur and patella during in vivo weightbearing knee flexion. Journal of Biomechanical Engineering. 129: 937-943.

Lonner JH. 2002. Patellofemoral arthroplasty: Current concepts. The University of Pennsylvania Orthopaedic Journal. 15:1-5.

Mann KA, Bartel DL, Wright TM, Ingraffe AR. 1991. Mechanical characteristics of the stem-cement interface. Journal of Orthopaedic Research. 9(6):798-808.

Mann KA, Miller MA, Pray CL, Verdonschot N, Janssen D. 2012. A new approach to quantify trabecular resorption adjacent to cemented knee arthroplasty. Journal of Biomechanics. 45:711-715.

Matthews LS, Sonstegard DA, Henke JA. 1977. Load bearing characteristics of the patello-femoral joint. Acta Orthopaedica. 48(5):511-516.

McKeever DC. 1955. Patellar prosthesis. The Journal of Bone and Joint Surgery. 37:1074-1084.

Meireles S, Completo A, Simoes JA, Flores P. 2010. Strain shielding in distal femur after patellofemoral arthroplasty under different activity conditions. Journal of Biomechanics. 43(3):477-484.

Mont MA, Leadbetter WB, Kolisek FR, Levitt RL, Brooker AF, Zietz P, Marker DR, Bonutti PM. 2008. Patellofemoral arthroplasty: a multi-centre study with minimum 2-year follow-up. International Orthopaedics. Springer Berlin.

Müller JH, Erasmus PJ, Scheffer C. 2012. Comparison of commercial patellofemoral arthroplasty systems on the basis of patella kinematics, peri-patellar soft tissue tension and prosthesis design. Journal of Mechanics in Medicine and Biology. 12 (5): art. no. 1250086.

Olsen M, Davis ET, Whyne CM, Zdero R, Schemitsch EH. 2010. The biomechanical consequence of insufficient femoral component lateralization and exposed cancellous bone in hip resurfacing arthroplasty. Journal of Biomechanical Engineering. 132(8):081011, 7p.

Reilly DT, Martens M. 1972. Experimental analysis of the quadriceps muscle force and patello-femoral joint reaction force for various activities. Acta Orthopaedica. 43:126-137.

Rubin CT, Lanyon LE. 1985. Regulation of bone mass by mechanical strain magnitude. Calcified Tissue International. 37:411-417.

Smith AM, Peckett WR, Butler-Manuel PA. 2002. Treatment of patello-femoral arthritis using the Lubinus patello-femoral arthroplasty: a retrospective review. Knee. 9:27-30.

Smith, RL, Schurman DJ, Maloney WJ. 2008. Localized osteoporosis. In: Marcus R, Feldman D, Nelson DA, Rosen CJ. Osteoporosis. Academic Press, 3th ed. p. 1417-1434.

Soininvaara TA, Miettinen HJA, Jurvelin JS, Suomalainen OT, Alhava EM, Kröger HPJ. 2004. Periprosthetic tibial bone mineral density changes after total knee arthroplasty: One-year followup study of 69 patients. Acta Orthopaedica Scandinavica. 75:600-605.

Stolk J, Verdonschot N, Cristofolini L, Toni A, Huiskes R. 2002. Finite element and experimental models of cemented hip joint reconstructions can produce similar bone and cement strains in pre-clinical tests. Journal of Biomechanics. 35(4):499-510.

Sumner DR, Galante JO. 1992. Determinants of stress-shielding: design versus materials versus interface. Clinical Orthopaedics Related Research. 274(12):202-212.

Tauro B, Ackroyd CE, Newman JH. 2001. The Lubinus patellofemoral arthroplasty: A 5 to 10 year prospective study. Journal of Bone and Joint Surgery- British Volume. 83:696-701.

Taylor M, Cotton J, Zioupos P. 2002. Finite element simulation of the fatigue behaviour of cancellous bone. Meccanica. 37:419-429.

van Jonbergen H-PW, Innocenti B, Gervasi GL, Labey L, Verdonschot N. 2012. Differences in the stress distribution in the distal femur between patellofemoral joint replacement and total knee replacement: A finite element study. Journal of Orthopaedic Surgery and Research. 7(1), art. no. 28. 
van Jonbergen HW, Poolman RW, van Kampen A. 2010. Isolated patellofemoral osteoarthritis: A systematic review of treatment options using the GRADE approach. Acta Orthopaedica. 81(2):199-205.

Wright TM, Burstein AH. 1994. Fundamentals of orthopaedic biomechanics. Williams and Wilkins. USA.

Zavatsky AB, Oppold PT, Price AJ. 2004. Simultaneous in vitro measurement of patellofemoral kinematics and forces. Journal of Biomechanical Engineering. 126:351-356. 
Table 1. Material properties

(Adapted from Completo et al. 2009 and Meireles et al. 2010)

\begin{tabular}{|c|c|c|c|}
\hline Component & Material & Young Modulus (GPa) & Poisson's Ratio \\
\hline Cancellous bone & Cancellous bone & 0.104 & 0.30 \\
\hline Compact bone & Compact bone & 16.700 & 0.30 \\
\hline Implant & Oxinium & 74.000 & 0.35 \\
\hline Cement layer & PMMA & 2.280 & 0.30 \\
\hline
\end{tabular}

Table 2. Loads by activity

(Adapted from Matthews et al. 1977)

\begin{tabular}{|c|c|c|c|}
\hline Activity & $\begin{array}{c}\text { Knee flexion } \\
\text { angle }\left({ }^{\circ}\right)\end{array}$ & $\begin{array}{c}\text { Tibiofemoral joint } \\
\text { reaction force (N) }\end{array}$ & $\begin{array}{c}\text { Patellofemoral joint } \\
\text { reaction force (N) }\end{array}$ \\
\hline Climbing stairs & 45 & 2963 & 1756 \\
\hline Descending stairs & 60 & 2668 & 1746 \\
\hline Isometric exercise & 90 & 2698 & 3424 \\
\hline
\end{tabular}




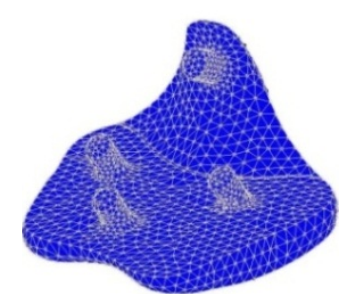

(a)

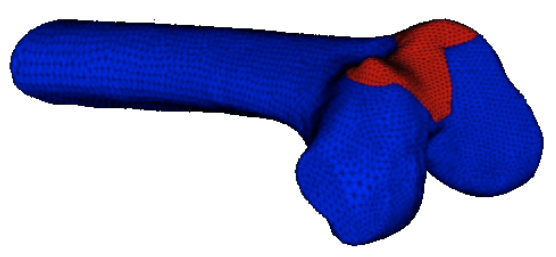

(b)

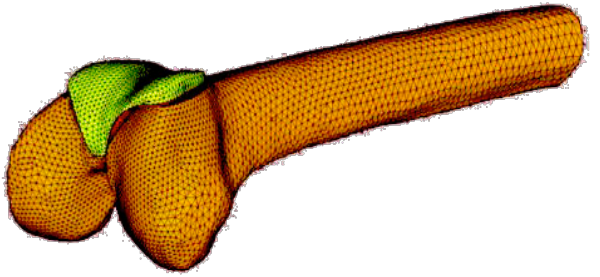

(c)

Figure 1. (a) FE models of Journey PFJ; (b) Natural femur; (c) Implanted femur with Journey PFJ

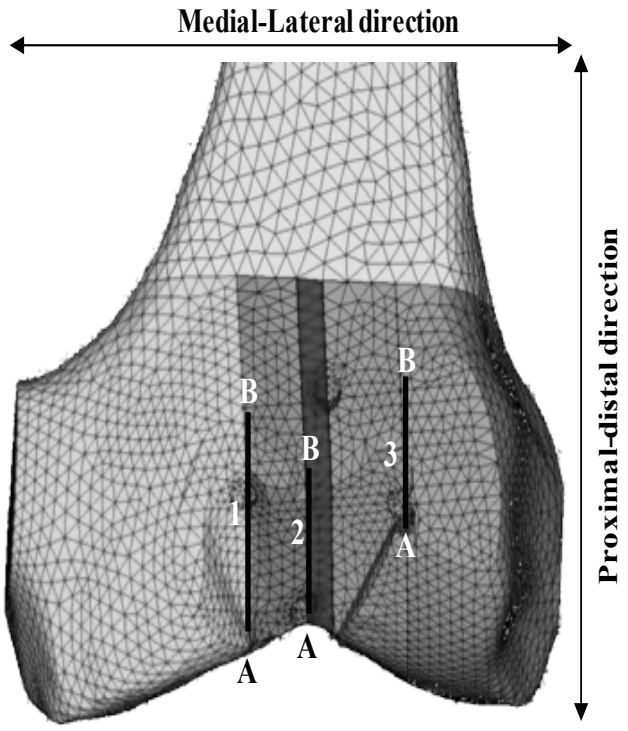

(a)

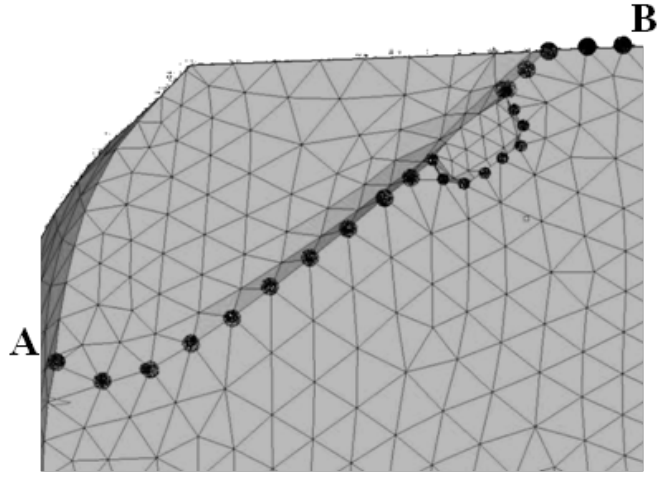

(b)

Figure 2. (a) Cancellous bone FE model; (b) Measurement lines

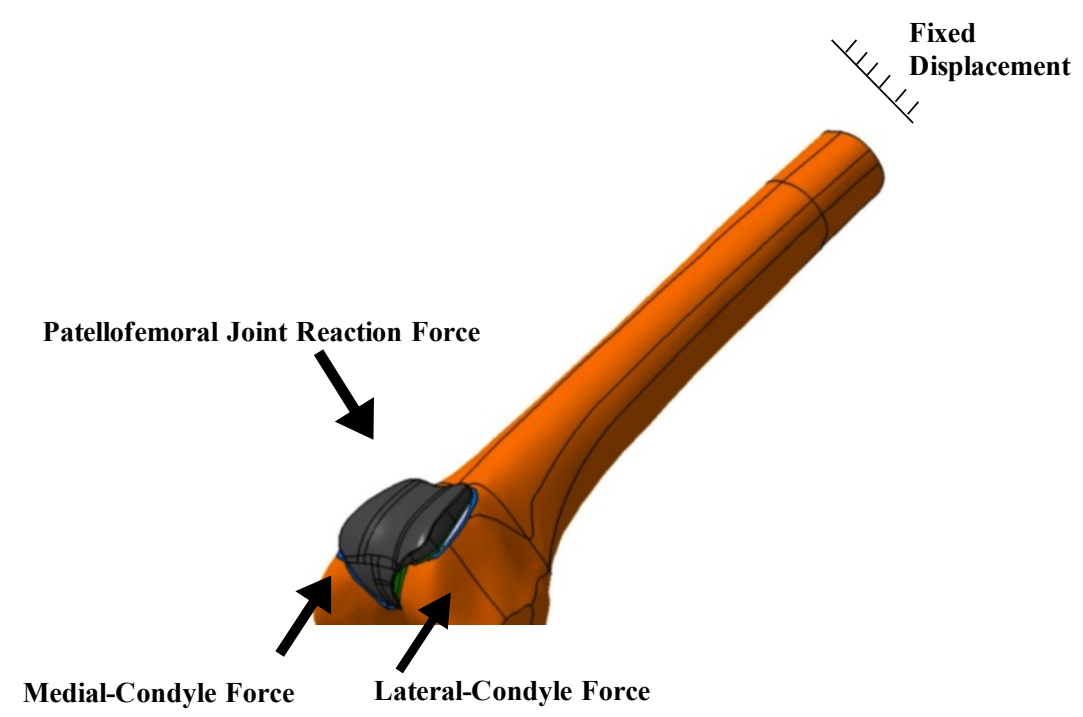

Figure 3. Boundary conditions applied to FE models 


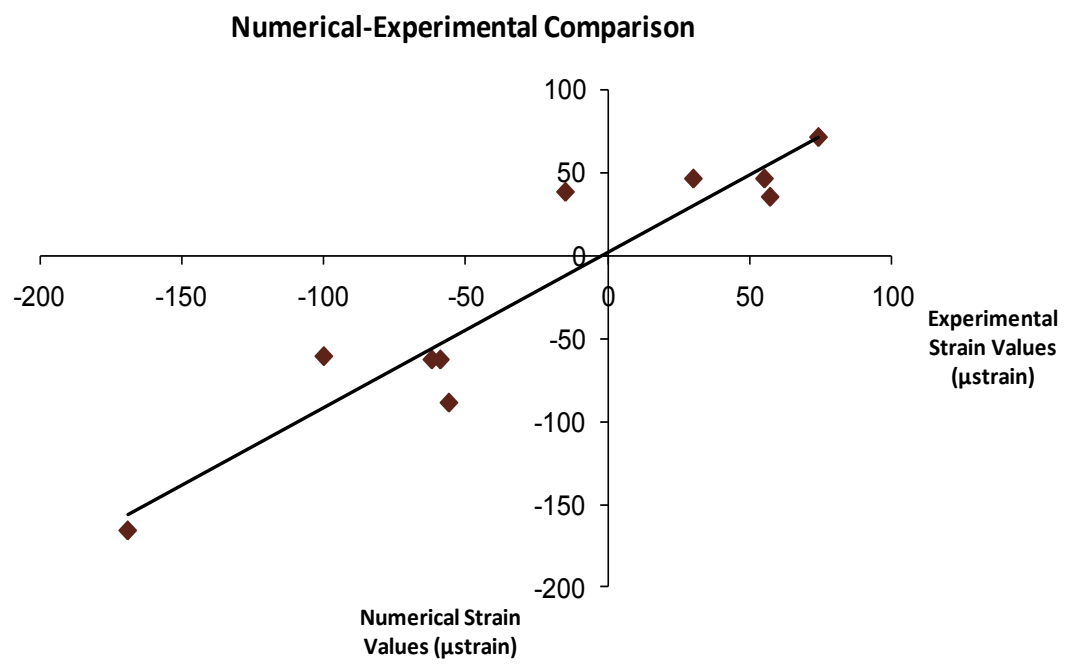

Figure 4. Linear regression curve for the numerical-experimental principal strain results in femur cortex, with the in-vitro measurements of Meireles et al. (2010).

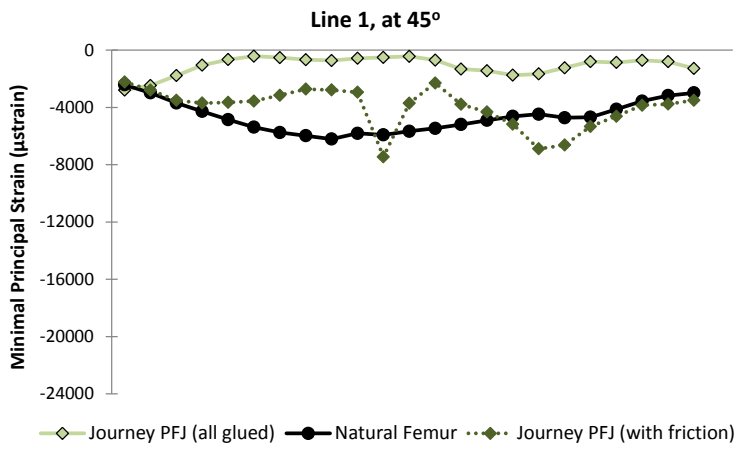

(a)

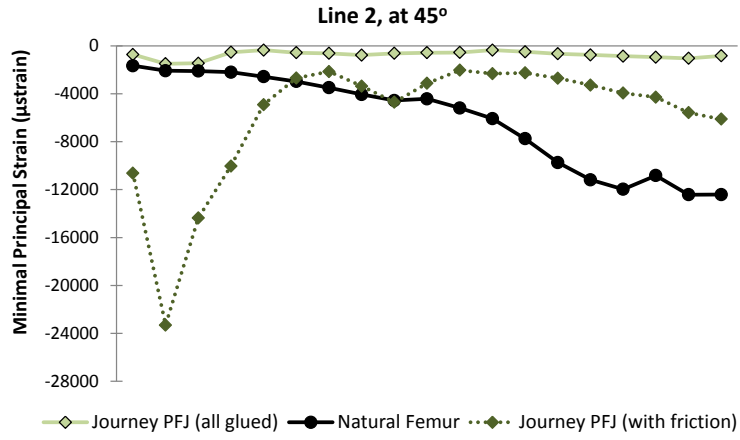

(b)

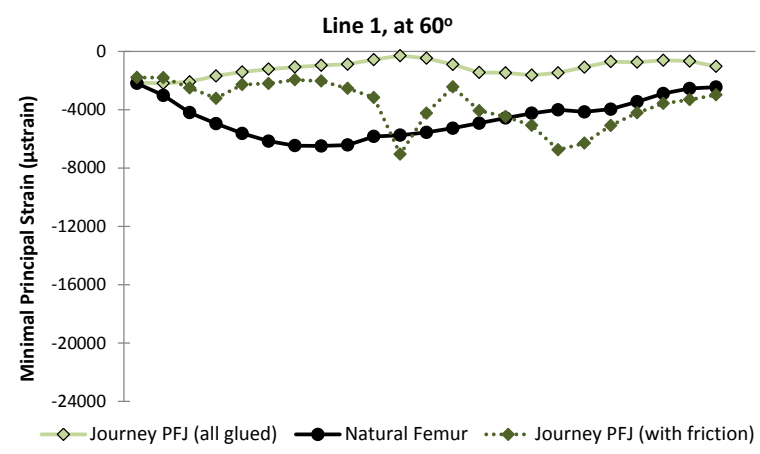

(d)

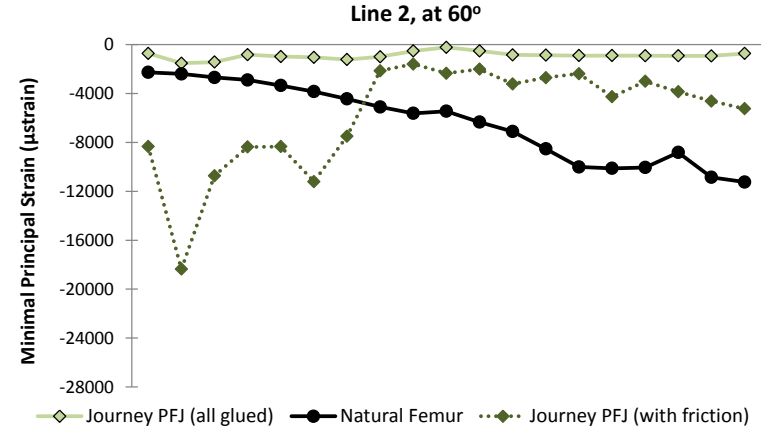

(e) 


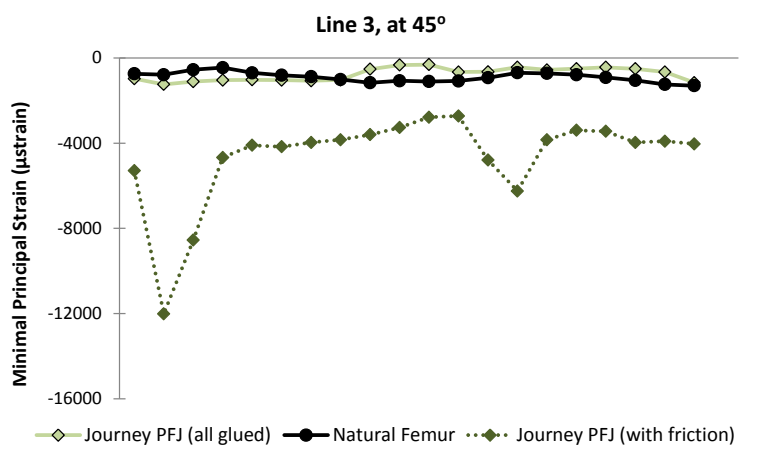

(c)

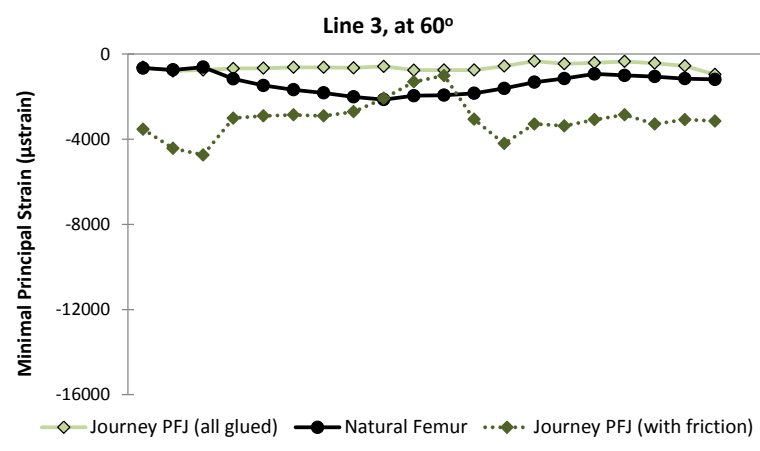

(f)

Figure 5. Minimal principal strain for different lines and degrees of knee flexion: (a) Line 1 at $45^{\circ}$, (b) Line 2 at $45^{\circ}$, (c) Line 3 at $45^{\circ}$, (d) Line 1 at $60^{\circ}$, (e) Line 2 at $60^{\circ}$, (f) Line 3 at $60^{\circ}$

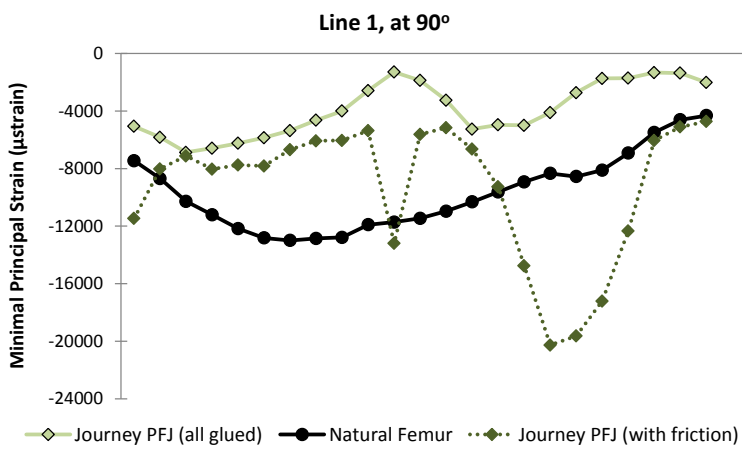

(a)

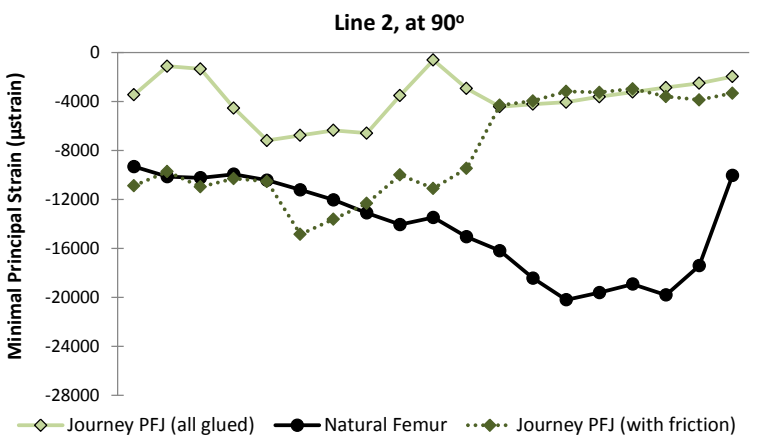

(b)

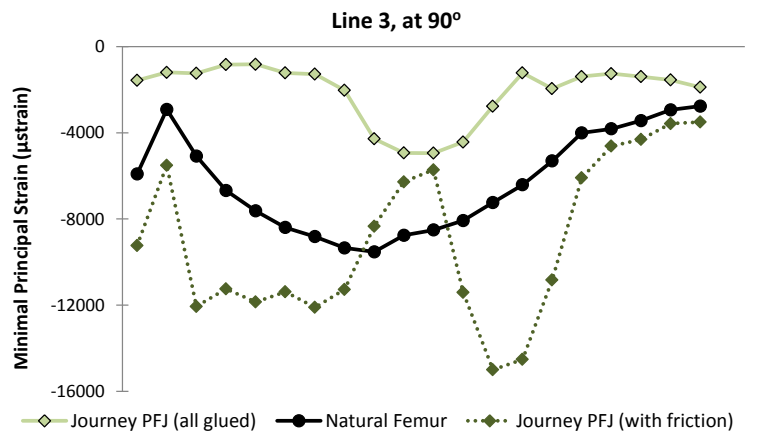

(c)

Figure 6. Minimal principal strain for different lines and 90 degrees of knee flexion: (a) Line 1, (b) Line 2, (c) Line 3 